\title{
COMPLEMENTARY MANIPULATOR TOOL DEVELOPMENT FOR SAFE COBOT-ASSISTED HYDROPONICS
}

\author{
IMRE PANITI*1,2, JÁNOS NACSA ${ }^{1,2}$, DÁVID SZÜR ${ }^{1}$, SÁNDOR RÁCZ ${ }^{3}$, AND JÓZSEF TÓTH ${ }^{4}$ \\ ${ }^{1}$ ELKH SZTAKI, Centre of Excellence in Production Informatics and Control, Kende u. 13-17, Budapest, \\ 1111, HUNGARY \\ ${ }^{2}$ Széchenyi István Egyetem, Egyetem tér 1, Győr, 9026, HUNGARY \\ ${ }^{3}$ Green Drops Farm Kft., Hold u. 56, Debrecen, 4034, HUNGARY \\ ${ }^{4}$ Hepenix Kft., Petőfi Sándor u. 39, Diósd, 2049, HUNGARY
}

\begin{abstract}
Human-robot collaboration is gaining ground in Manufacturing, Healthcare and Logistics but also in Agriculture. Different types of applications in the latter field are becoming more common. However, in all scenarios, safety assessment and verification are crucial to cope with the related standards and specifications. In this paper, the development and safety testing of a complementary manipulator tool (Clip) is presented which can by design limit the physical interaction energy in a hazardous collaborative robot (cobot) scenario, namely when loading the plant of a Hydroponic System.
\end{abstract}

Keywords: hydroponics, human-robot collaboration, safety

\section{Introduction}

Using robots in agriculture is a rather old field of interest with many difficult automation problems. Incorporating automation can help hydroponic systems become more efficient and productive because - according to Ref. [1] labor is the biggest cost in this domain. In a review [2] about smart hydroponic systems, some robotic applications were mentioned, e.g. harvesting strawberries and cleaning greenhouses. In the real business world, some companies offer completely robot-based hydroponic environments, e.g. a start-up called Iron Ox has just received a big investment [3] for their complete hydroponic farming solution. The safety aspects in indoor farming environments were also investigated [4]. In this paper, the technical criteria of a cobotised Hydroponic System are presented alongside the development of a complementary manipulator tool which is finally tested against a safety protocol.

\section{Technical criteria}

In order to create a safe, cobotised Hydroponic System, the Directive 2006/42/EC of the European Parliament and of the Council of 17 May 2006 on machinery [5], and amending Directive 95/16/EC (recast [6] needs to be applied, together with the Low Voltage Directive 2014/35/EU [7] which is applicable from 20th April 2016, i.e. the Council Directive 2006/95/EC of

\footnotetext{
*Correspondence: imre.paniti@sztaki.hu
}

12th December 2006 on the electrical equipment designed for use within certain voltage limits, amended by (93/68/Ě̌F) and the EMC directive (2014/30EU [8] applicable from 20th April 2016), that is, the Council Directive 2004/108/EC of 15th December 2004 on the approximation of the laws of the Member States relating to electromagnetic compatibility.

Furthermore, although a large number of initially considered harmonized standards are present, the main relevant ones are the following:

- ISO 13855:2010 [9] - Safety of machinery. Positioning of safeguards with respect to the approach speeds of parts of the human body.

- EN 547-3:2009 [10] - Safety of machinery. Human body measurements.

- ISO 14123-1:2015 [11] - Safety of machinery - Reduction of risks to health from hazardous substances emitted by machinery - Part 1: Principles and specifications for machinery manufacturers.

- EN 1005-1:2001+A1:2008 [12] - Safety of machinery - Human physical performance - Part 1: Terms and definitions.

- EN 1005-3:2002+A1:2008 [13] - Safety of machinery - Human physical performance - Part 3: Recommended force limits for machinery operation.

- ISO 10218-1:2011 [14] - Robots and robotic devices. Safety requirements for industrial robots. 


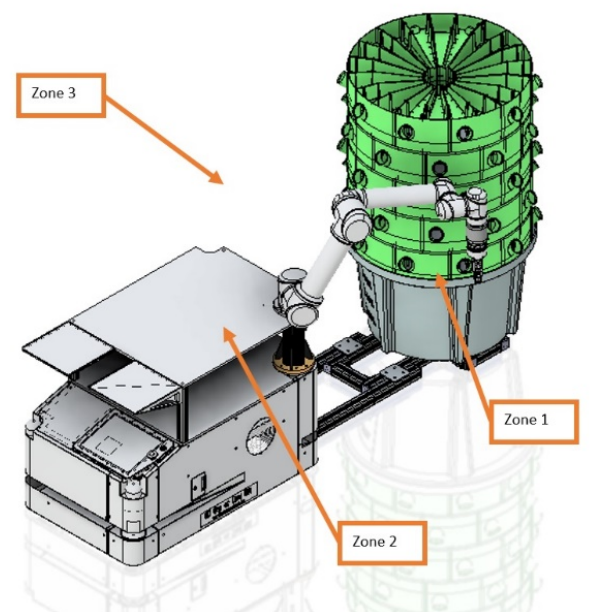

Figure 1: Set-up of the Cobotised Hydroponic System with 3 Zones.

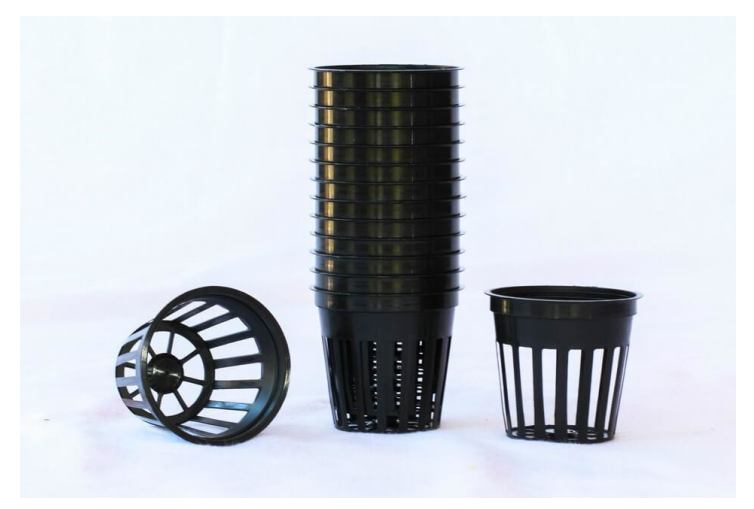

Figure 2: Hydro pot.

- ISO 3691-4:2020 [15] - Industrial trucks. Safety requirements and verification - Part 4: Driverless industrial trucks and their systems.

- IEC 61508-3:2010 [16] - Functional safety of electrical/electronic/programmable electronic safetyrelated systems - Part 3: Software requirements.

- SIST EN 61508-5:2011 [17] - Functional safety of electrical/electronic/programmable electronic safety-related systems - Part 5: Examples of methods for the determination of safety integrity levels.

The technical specification, ISO/TS 15066:2016 [18] Robots and robotic devices - Collaborative robots, should also be taken into consideration.

These directives and standards were necessary because the cobotised Hydroponic System consists of an UR5 cobot arm mounted on an Automated Ground Vehicle (AGV) which is docked to the hydroponic growing tower with an electric pump (see Fig. 1).

Based on the set-up, 3 hazard zones were defined:

- Zone 1: Primary process area

- Zone 2: Secondary process area

- Zone 3: Surrounding equipment

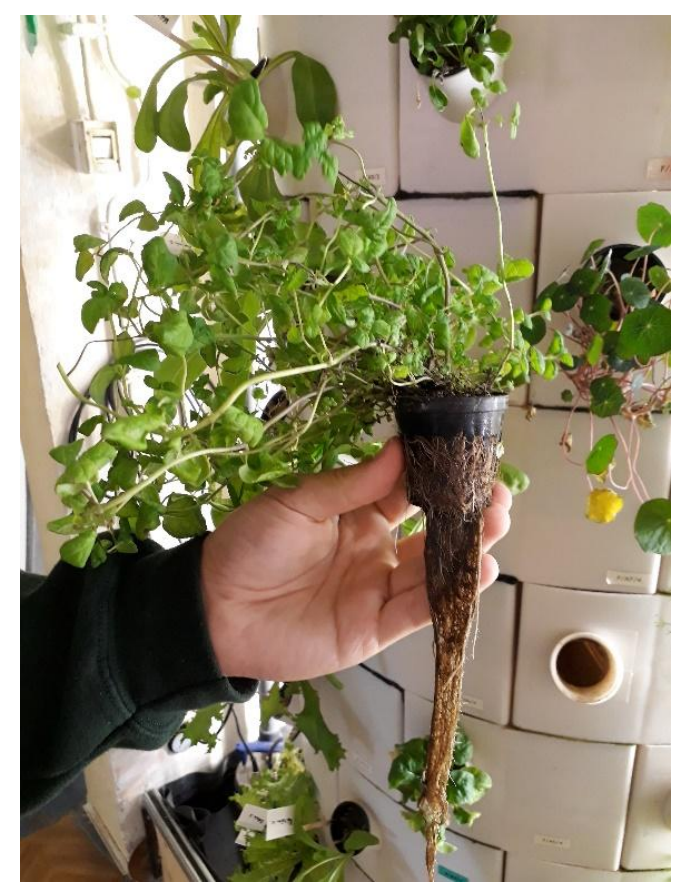

Figure 3: Plant roots in the Hydro pot.

\section{Risk assessment}

The risk analysis was carried out for Zone 1 according to a normal methodology, following the steps of the ISO 12100:2010 standard [19]. After recognizing the hazards and the injuries, a risk graph had to be categorized based on ISO 13849-1:2015 [20]. As a result of the categorization, the risk level of each hazard could be calculated. The risk level of each hazard was calculated using the worst result.

As the cobot arm is equipped with a two-finger gripper and is responsible for loading the seedlings, this is one of the crucial elements of the system in terms of safety. Special care needs to be taken when manipulating the plants as on the one hand, damage to the crops, leaves and roots should be avoided, but on the other hand an unintended collision with a plant carrier should not exceed the biomechanical threshold values defined in Ref. [18].

\section{Clip development}

Green Drops Farm Kft. developed its hydroponic system using a commercially available product called a hydro pot (see Fig. 2) with a diameter of $50 \mathrm{~mm}$ for creating holes to plant plants by following the same practices adopted by similar pieces of equipment.

During the development of automation and robotization, a problem occurred, namely that as the crops grow their roots overgrow the hydro pot so the plant becomes stuck where it is (see Fig. 3). As a result, the arm of the cobot is unable to handle the pots, which cannot be used again.

In order to be sustainable and recycle, several versions of clips have been designed and commercially available rockwool cubes used. 


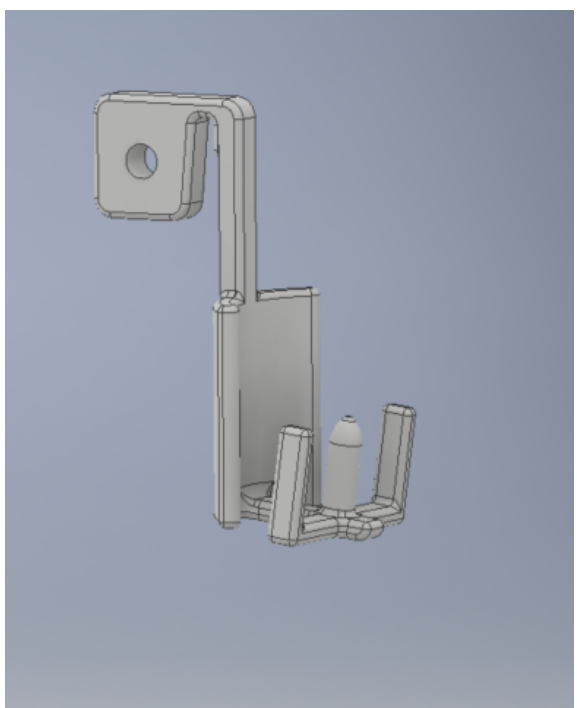

Figure 4: One of the first clip prototypes.

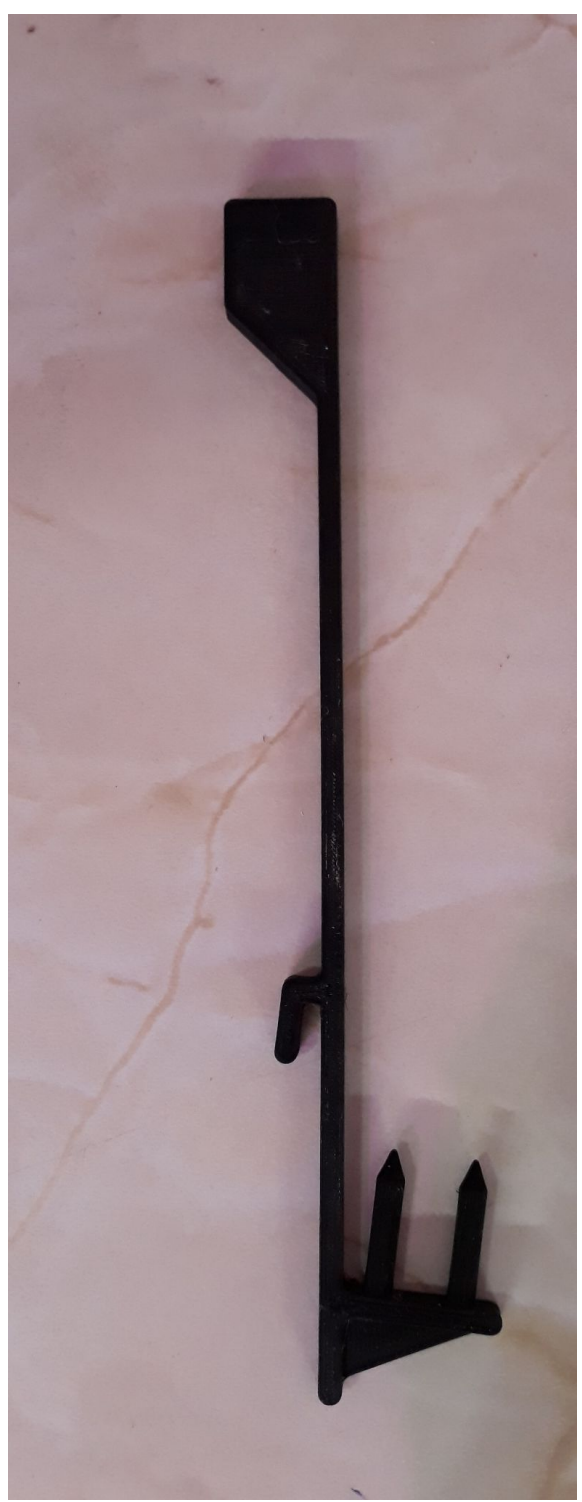

Figure 5: Clip prototypes with vertical spikes.

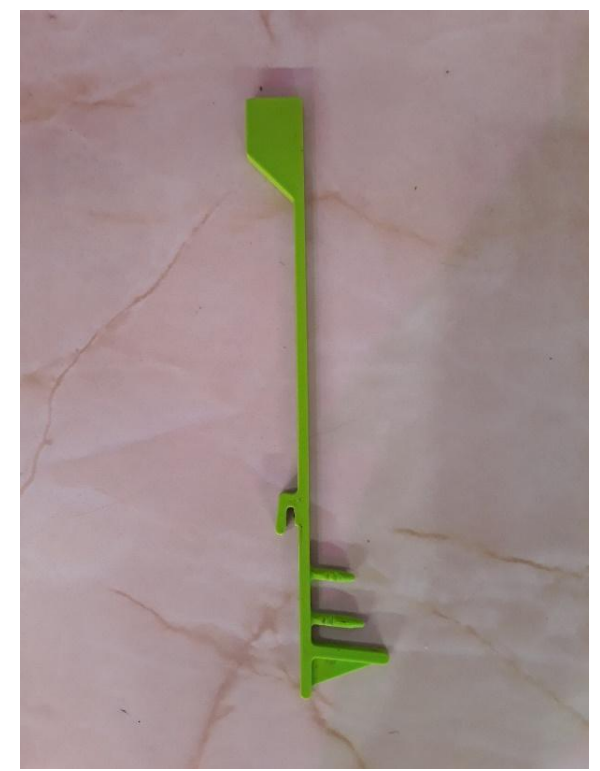

Figure 6: Clip prototypes with horizontal spikes.

As the cobot arm could not handle the clips because the part (a flag-like handle) it would grab (see Fig. 4) had become overgrown by the plant, that part had to be redesigned.

In the first versions of the design, the spike on the clips was vertical, but during testing it was demonstrated that it could cause serious injuries to people (see Fig. 5), despite the fact that the clips had been created using 3D printing.

The end of the spike needed to be blunted and placed horizontally in order to avoid causing potential injuries (see Fig. 6). Even though horizontal rockwool cubes were produced to facilitate its installation, the plants could still fall off.

In the final version, nooks were placed on the clips on which semicircular plant holder rings can be placed at different heights. This prevents plants from falling off and it is safer moving them using the cobot arm (see Fig. 7).

\section{Collision tests}

Tests were carried out on the clips according to a testing protocol entitled "Test robot arm for collision with movable object (Impact)" from the COVR Toolkit [21], which functions also as a library for protocol testing of cobot applications. These tests are in harmony with the standards within the frame of cobot usage as described in Ref. [22]. Force measurements were recorded with a GTE KMG 500-75 force cell (Spring rate: $75 \mathrm{~N} / \mathrm{mm}$ with the damping material SH70) while pressure values were measured with Fuji Prescale LLW-type Films (see Fig. 8).

The results of 3 experiments at a cobot speed of 0.1 $\mathrm{m} / \mathrm{s}$ showed that for a human hand only a transient collision can occur with a maximum force of $47 \mathrm{~N}$ (see Fig. 


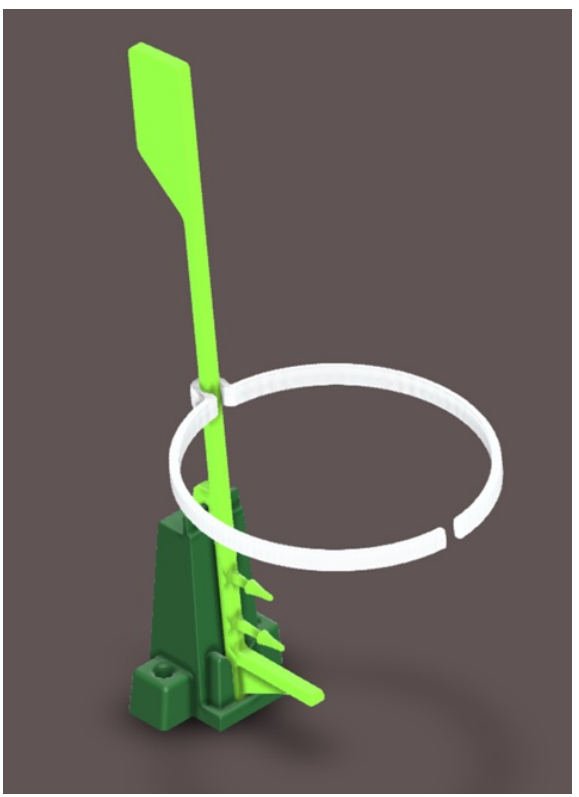

Figure 7: Final clip design with a clip and plant holder.

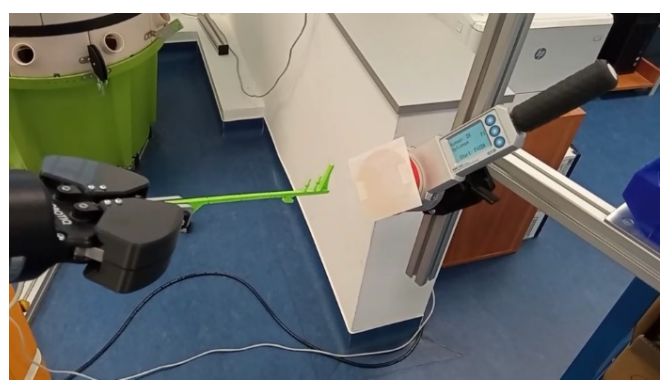

Figure 8: Clip collision testing set-up with a force cell and pressure-sensitive measurement film.

9) as in all cases the 3D-printed clip breaks at the same position.

The maximum pressure was $300 \mathrm{~N} / \mathrm{cm} 2$ (see Fig. 10).

As in some cases the pressure can be close to the threshold, the use of gloves while carrying out clipassisted plant loading is highly recommended.

\section{Conclusion}

Hydroponics is a subset of hydroculture, which is an environmentally friendly technology for growing plants in the absence of soil by using mineral nutrient solutions dissolved in water. Many tasks in the Hydroponic production process cannot be fully automated and require safe human-robot collaboration, moreover, cobotised tasks like the loading of plants must be tested with a safety protocol similar to the one followed in this paper. The proposed 3D-printed complementary manipulator tool (clip) was tested by following the protocol "Test robot arm for collision with movable object (Impact)." Test results showed that only transient collisions can occur and force as well as pressure values are below the threshold in the case of a collision with a human hand.

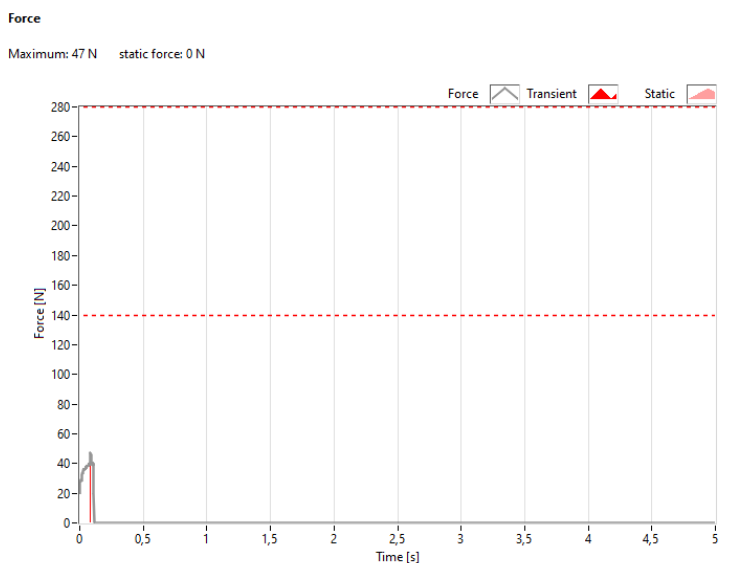

Figure 9: Force measurement results.

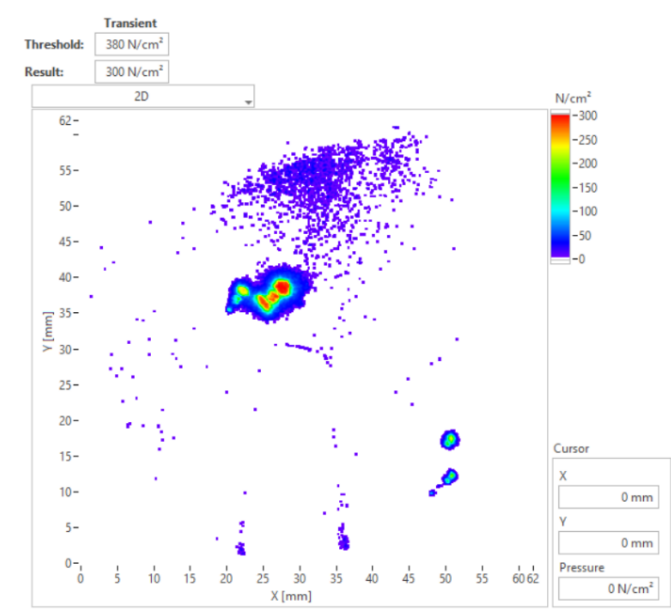

Figure 10: Pressure measurement results.

However, to maximize safety, it is recommended that gloves are worn.

\section{Acknowledgement}

This project was funded by the European Union's Horizon 2020 research and innovation programme under grant agreement No. 779966. Furthermore, this research was supported by the 'Thematic Excellence Programme - National Challenges Subprogramme - Establishment of the Center of Excellence for Autonomous Transport Systems at Széchenyi István University (TKP2020-NKA14)' project.

\section{REFERENCES}

[1] Currey, C. J.: Automation for hydroponics, Produce Grower, 2019 https://www.producegrower.com

[2] Modu, F.; Adam, A.; Aliyu, F.; Mabu, A.; Alhaji Musa, M.: A Survey of Smart Hydroponic Systems. Advances in Science, Technology and Engineering Systems Journal, 2020, 5, 233-248 DOI: 10.25046/aj050130 
[3] Leading Ag-Tech Start-up Iron Ox Closes \$53 Million Investment Round Led by Breakthrough Energy Ventures (news); https://ironox.com

[4] Gnauer, C.; Pichler, H.; Tauber, M.; Schmittner, C.; Christl, K.; Knapitsch, J.; Parapatits, M.: Towards a secure and self-adapting smart indoor farming framework. Elektrotechnik und Informationstechnik 2019, 136(7), 341-344 DOI: 10.1007/s00502-019-00745-0

[5] Directive 2006/42/EC, https://eur-lex.europa.eu

[6] Directive 95/16/EC, https://eur-lex.europa.eu

[7] Directive 2014/35/EU, https://eur-lex.europa.eu

[8] Directive 2014/30/EU, https://eur-lex.europa.eu

[9] ISO 13855:2010, https://www.iso.org

[10] EN 547-3:2009, https://webstore.ansi.org

[11] ISO 14123-1:2015, https://www.iso.org

[12] EN 1005-1:2002+A1:2008, https://standards.iteh.ai
[13] EN 1005-3:2002+A1:2008, https://standards.iteh.ai

[14] ISO 10218-1:2011, https://www.iso.org

[15] ISO 3691-4:2020, https://standards.iteh.ai

[16] EN 61508-3:2010, https://standards.iteh.ai

[17] EN 61508-5:2011, https://standards.iteh.ai

[18] ISO/TS 15066:2016, https://www.iso.org

[19] ISO 12100:2010, https://www.iso.org

[20] ISO 13849-1:2015, https://www.iso.org

[21] COVR Toolkit. https://www.safearoundrobots.com/home

[22] Valori, M.; Scibilia, A.; Fassi, I.; Saenz, J.; Behrens, R.; Herbster, S.; Bidard, C.; Lucet, E.; Magisson, A.; Schaake, L.; Bessler, J.; Prange-Lasonder, G.B.; Kühnrich, M.; Lassen, A.B.; Nielsen, K.: Validating Safety in Human-Robot Collaboration: Standards and New Perspectives. Robotics, 2021, 10, 65. DOI: 10.3390/robotics 10020065 